\title{
Os Propósitos da Avaliação nas Feiras de Matemática
}

\author{
The Purposes of Evaluation in Mathematics Fairs
}

\author{
Morgana Scheller* \\ ORCID iD 0000-0002-1704-0565 \\ Marília Zabel $^{* *}$ \\ ORCID iD 0000-0003-3124-7690
}

\begin{abstract}
Resumo
O Movimento Feiras de Matemática constitui um espaço que incentiva, divulga e socializa experiências de sala de aula, pesquisas e atividades matemáticas desenvolvidas, principalmente na Educação Básica. Santa Catarina já possui 35 edições e, recentemente, vem se destacando no cenário nacional. Nesse Movimento, o processo de avaliação ${ }^{1}$ tem sido sempre polêmico por conta do resultado referente à indicação dos trabalhos e pela descrição qualitativa feita pelos avaliadores. Assim, este artigo buscou compreender as significações que emergem dos registros de avaliação dos trabalhos expostos na Feira, a partir dos propósitos de avaliação defendidos no Movimento. Trata-se de uma pesquisa de natureza qualitativa e cunho interpretativo, cujo processo de investigação se deu por meio de estudo documental. Os dados são constituídos pelas fichas de avaliação que integram o relatório final de duas Feiras Regionais de Matemática realizadas em 2017. Assim, foram analisadas 225 fichas de avaliação oriundas de 71 trabalhos expostos, por meio dos procedimentos da Análise Textual Discursiva (ATD). Da análise emergiram quatro categorias que descrevem as significações da avaliação: avaliação como meio para validar/verificar, para aferir, para desqualificar e para sugerir/propor. Identificou-se que as avaliações se concentram nos propósitos de examinar e classificar e que as considerações propositivas, características de uma avaliação formativa, estão diretamente relacionadas com a concepção do avaliador. Conclui-se, para tanto, que é necessário constantemente investir na formação dos professores orientadores e dos avaliadores que participam do Movimento.
\end{abstract}

Palavras-chave: Feiras de Matemática. Fichas de Avaliação. Concepção de Avaliação.

\begin{abstract}
The Mathematics Fairs Movement is a space that encourages, disseminates, and socializes classroom experiences, research and mathematical activities developed mainly in Basic Education. Santa Catarina has already had 35 editions of the fair and, recently, has been standing out on the national scene. In this Movement, the evaluation process has always been controversial due to the indication result of the works and the qualitative description made by the evaluators. Thus, this article sought to understand the meanings that emerge from the evaluation records of the works exhibited at the Fair, based on the evaluation purposes defended in the Movement. It is a qualitative and interpretative research, which investigation process took place through documentary study. The data are made up of the assessment forms that are part of the final report of two

\footnotetext{
* Doutora em Educação em Ciências e Matemática pela Pontifícia Universidade Católica do Rio Grande do Sul (PUCRS). Docente do Instituto Federal Catarinense (IFC), Rio do Sul, Santa Catarina, Brasil. Endereço para correspodência: Rua São José, 384, Centro, Atalanta, Santa Catarina, Brasil, CEP: 88410-000. E-mail: morgana.scheller@ifc.edu.br

** Doutoranda em Educação Matemática pela Universidade Estadual Paulista "Júlio de Mesquita Filho" (UNESP). Docente do Instituto Federal Catarinense (IFC), Rio do Sul, Santa Catarina, Brasil. Endereço para correspondência: Rua Elisabeth Jasper, 114, apto 102, Fundo Canoas, Rio do Sul, Santa Catarina, Brasil, CEP: 89163-155. E-mail: marilia.zabel@ifc.edu.br.

${ }^{1}$ Neste artigo, a expressão 'processo de avaliação nas Feiras' refere-se ao processo de avaliação dos trabalhos que são expostos pelos participantes no dia da Feira e avaliados por um grupo de avaliadores.
} 
Regional Mathematics Fairs held in 2017. Thus, 225 assessment sheets from 71 works were analyzed, through the procedures of the Textual Discursive Analysis (ATD). From the analysis, four categories emerged describing the meanings of the evaluation: evaluation as a means to validate/verify, to measure, to disqualify, and to suggest/propose. It was identified that the evaluations focus on the purposes of examining and rating and that the propositional considerations, characteristic of a formative evaluation, are causally related to the evaluator's conception. We conclude, therefore, that it is necessary to constantly invest in the training of guiding teachers and evaluators who participate in the Movement.

Keywords: Mathematics Trade Shows. Evaluation Sheets. Evaluation Conception.

\section{Introdução}

O Movimento Feiras de Matemática recentemente vem se destacando dentre as ações relacionadas à Educação Matemática, fato que já permitiu a realização de mostras no Encontro Nacional de Educação Matemática (ENEM). Nas Feiras participam, principalmente, profissionais de ensino e estudantes da Educação Básica. Santa Catarina foi o primeiro estado brasileiro a realizá-las, sendo a primeira edição do evento anual registrada no ano de 1985 e, desde então, envolve a cada edição cerca de cinco mil pessoas. Atualmente o Movimento já acontece em outros estados, sendo identificadas edições organizadas e desenvolvidas em nível escolar, municipal, regional, estadual e nacional. Estudos como os de Zermiani (1996), Zermiani, Jubini e Souza (2015), Biembengut e Zermiani (2014) e Silva e Garnica (2015) apresentam considerações a respeito do histórico das Feiras de Matemática, contexto esse existente devido a um projeto iniciado pelos professores José Valdir Floriani e Vilmar José Zermiani (ZERMIANI, 1996).

Em sua gênese, as Feiras de Matemática constituem uma das alternativas buscadas pelos educadores matemáticos catarinenses para superar as tradicionais práticas que predominavam no ensino de Matemática (ZERMIANI, 1996). A Feira trata-se de “[...] um processo educativo científico-cultural, que alia vivências e experiências" (REGIMENTO, 2018, p. 1), bem como “[...] um momento de socialização dos conhecimentos matemáticos e experiências pedagógicas produzidos pelos expositores e orientadores" (DAMÁZIO; TOMELIN, 2002, p. 84) das várias etapas da Educação Básica e Superior, geralmente nas salas de aula ou em ambiente escolar.

Assim, destaca-se que as Feiras foram idealizadas para ser um espaço de socialização e divulgação de experiências, estudos e atividades matemáticas desenvolvidas no âmbito escolar, principalmente nas salas de aula. Por outro lado, também se constituem em oportunidade de incentivo aos participantes, visitantes e outros professores a reproduzirem ou adaptarem práticas exitosas para a sala de aula. Dessa forma, as Feiras também 
se constituem numa experiência curricular ou extracurricular de relevância para sistematizar e implementar os Projetos e/ou Programas de Educação Científica dos Alunos e Professores, contribuindo para inovação curricular, durante o ano letivo, nas instituições envolvidas (REGIMENTO, 2018, p. 1).

Participam das Feiras de Matemática estudantes e professores de todos os níveis da Educação Básica e Superior, organizados nas seguintes categorias: Educação Especial, Educação Infantil, Ensino Fundamental - Anos Iniciais, Ensino Fundamental - Anos Finais, Ensino Médio, Ensino Superior e Professor. Ainda, independente do grau de escolaridade, há a categoria Comunidade. A exposição dos trabalhos é realizada por dois estudantes que devem estar na mesma etapa de escolaridade, exceto nas categorias professor e comunidade. No ato da inscrição dos trabalhos é apresentado um relato de experiência e/ou pesquisa, com modelo aprovado no Seminário das Feiras ${ }^{2}$, para posterior publicação nos anais do evento, quando se referem às etapas estaduais ou nacionais.

As experiências, os estudos ou as atividades socializadas durante as edições, por deliberação dos participantes, são avaliadas por profissionais da área, tais como professores orientadores, coordenadores pedagógicos, licenciandos de Matemática e Pedagogia, dentre outros. A avaliação dos trabalhos é feita em grupos de três ou quatro membros, que individualmente: (i) fazem a leitura do relato de experiência e/ou pesquisa; (ii) assistem à apresentação oral; (iii) emitem, em uma ficha de avaliação, um parecer escrito sobre cada trabalho observado e conhecido. Após, reúnem-se no coletivo (coordenados por um dos membros do grupo) para juntos emitirem considerações gerais sobre cada trabalho na forma de um relatório síntese. Posterior à exposição, esse relatório é encaminhado aos autores do trabalho pela comissão de avaliação.

Tal processo de avaliação é um tema polêmico e provoca inquietações no âmbito do Movimento Feiras de Matemática, conforme destacado em Breukman (1996), Damázio e Tomelin (2002), Tomelin (2004), Scheller e Gauer (2006), Civiero, Possamai e Andrade Filho (2015), dentre outros. Duas são as principais polêmicas: (i) o resultado da avaliação referente à indicação dos trabalhos como destaque ou menção honrosa; (ii) as considerações qualitativas expressas pelos avaliadores e constantes nas fichas de avaliação. No entanto, de acordo com as deliberações do Movimento ocorridas ao final de cada edição e dos Seminários que discutem o futuro do Movimento, os participantes anseiam que a avaliação permaneça.

A partir da vivência e observação durante o Movimento Feiras, da participação em Seminários de Avaliação das Feiras e em projetos que promovem a formação de professores e

\footnotetext{
${ }^{2}$ Para mais informações e acesso aos Anais dos Seminários e de Feiras, viste o site do Movimento disponível em: http://www.sbembrasil.org.br/feiradematematica/anais.html.
} 
avaliadores para o evento, percebeu-se que a avaliação ainda não está atendendo aos propósitos dos envolvidos, principalmente dos expositores e orientadores. Apesar das formações realizadas para o processo de avaliação e discussões existentes nos grupos de avaliação durante a realização da maioria das Feiras, é comum, nos bastidores, professores orientadores e estudantes, por vezes descontentes com a avaliação realizada, sentindo-se injustiçados com o resultado.

Em outra perspectiva, a Comissão de Avaliação almeja sempre um processo de avaliação de caráter formativo (HADJI, 2001), coletivo e colaborativo, destacando sempre que a Feira tem propósito de socialização e não de competição. Esses são os princípios balizadores do processo avaliativo no Movimento Feiras - avaliação como processo dinâmico que busca subsidiar as ações do professor orientador e dos estudantes para a qualificação do trabalho desenvolvido e exposto (CIVIERO; POSSAMAI; ANDRADE FILHO, 2015).

Nesse contexto, iniciou-se um estudo a respeito da avaliação e de sua concepção nas Feiras. Supõe-se que a polêmica gerada pode ser em decorrência das fichas de avaliação que contêm os registros escritos pelos avaliadores e retornam aos autores do trabalho. Partindo do pressuposto de que o problema poderia residir nesse aspecto, buscou-se respostas para as seguintes indagações: Que significações emergem dos registros de avaliação expressos nas fichas dos trabalhos expostos em Feiras de Matemática? De que forma esses registros atendem aos propósitos de avaliação defendidos no Movimento?

Assim, este estudo objetivou compreender as significações dos registros de avaliação dos trabalhos expostos em duas Feiras Regionais, a partir dos propósitos de avaliação defendidos no Movimento. Supõe-se que, embora a avaliação seja expressa por meio de proposições qualitativas, as considerações dos avaliadores não contemplam os ideais de avaliação defendidos no Movimento, servindo mais para aferir resultado e expressar críticas não construtivas, sendo desprovidas, em sua maioria, de função propositiva e contributiva que propiciam ampliação e qualificação do trabalho. Com base nisso, sendo as Feiras de Matemática concebidas e construídas a partir de um contexto coletivo e colaborativo, este estudo contribui com o processo de avaliação tanto dos trabalhos apresentados, quanto da própria Feira, a fim de que o Movimento possa avançar minimizando os efeitos negativos da avaliação que o permeia.

\section{A concepção de avaliação nas discussões que envolvem Feiras de Matemática}

As Feiras de Matemática, em Santa Catarina, tiveram seu processo iniciado, como já 
mencionado, em 1985 (ZERMIANI, 1996). No entanto, as pesquisas sobre o objeto ainda são reduzidas, embora existam informações publicizadas envolvendo o tema. Identificou-se, na revisão realizada, a presença de três números temáticos publicados em periódicos, sendo um de 1996, marcando os primeiros registros do tema, outro em 2016 e, recentemente, o último em 2019. Também foram identificadas publicações na forma de livros de autoria, tanto individual, quanto coletiva, anais das feiras (Estaduais e Nacionais), anais dos Seminários de Avaliação das Feiras e boletins informativos, bem como artigos e relatos publicados em eventos. Complementam a revisão os estudos desenvolvidos em dissertações e uma tese.

Essas publicações, em grande parte, têm foco na socialização das experiências e atividades desenvolvidas na, para e durante a feira, sendo incipientes aquelas cujo foco é a análise de temas ou tópicos específicos que permeiam o Movimento, dentre elas, o processo de avaliação dos trabalhos. Dentre estudos e reflexões identificadas, que tem como objeto principal a avaliação, destacam-se os estudos de Breuckmann (1996), Damázio e Tomelin (2002), Gauer (2004), Scheller e Gauer (2006), Civiero, Possamai e Andrade Filho (2015), Silva e Possamai (2019), dentre outros. No entanto, nenhum deles foi realizado a partir dos materiais produzidos durante a Feira, como as fichas de avaliação, por exemplo.

Desses estudos e reflexões a respeito do tema avaliação, os primeiros foram feitos por Breuckmann (1996). Considerando que a avaliação faz parte de qualquer etapa da atividade pedagógica e que as Feiras constituem-se de um momento dessa atividade, o autor já sinalizava que o processo avaliativo dos trabalhos apresentados numa Feira possui peculiaridades, uma vez que os avaliadores não vivenciam o processo percorrido pelos demais envolvidos.

Ainda que Breuckmann (1996) observe essa questão, ele não apresenta uma concepção para o ato de avaliar os trabalhos na Feira, mas aponta inúmeras dificuldades para uma avaliação ideal, como: tempo disponível para sua operacionalização; a pressão do orientador; dificuldade de realizar avaliação participativa; dentre outros. A partir disso, o autor sugere alternativas para a operacionalização dela, que considerava a necessidade de um espaço para avaliação que envolvesse orientadores, expositores e avaliadores, bem como uma mudança nos critérios de avaliação existentes na época e ampliação no número de fontes para realização da avaliação, como relatórios, portfólios, diário de bordo, dentre outros.

Já Damázio e Tomelin (2002) expõem que desde as primeiras Feiras há controvérsias a respeito da avaliação. Os autores identificaram duas correntes de pensamento perceptivas de avaliação: (i) a avaliação cuja finalidade é classificar os trabalhos de acordo com os critérios estabelecidos para indicar a premiação; (ii) avaliação como busca de sugestão para o 
aprimoramento e continuidade do trabalho.

Pode-se observar que, das duas perspectivas de avaliação descritas, a primeira traz à tona a meritocracia, a competição, a seleção e a exclusão como principais finalidades da avaliação constituindo, assim, como atividade produto. Já os defensores da segunda corrente compreendem a avaliação como processual e contínua, como uma atividade que visa o aprimoramento, a melhoria, a superação e o aperfeiçoamento. Dessa forma, ao pensar um trabalho para a Feira, a preocupação não deveria estar centrada no avaliador e no entendimento que ele tem dos critérios, afinal, estes são subjetivos e dão margem à múltiplas interpretações.

Os autores, ao defenderem a segunda corrente de pensamento, sugerem que a avaliação cumprirá com sua finalidade se o avaliador estiver atento "[...] às evidências do objeto de estudo, aos objetivos, à metodologia adotada, à apresentação e aos resultados apresentados" (DAMÁZIO; TOMELIN, 2002, p. 87). Também argumentam que um feedback da avaliação ao grupo pode ser importante e necessário para que o trabalho possa ser melhorado e enriquecido. Assim, defendem a necessidade de ultrapassar o caráter classificatório existente até então. A partir disso, surge a necessidade de pensar uma avaliação processual mais qualitativa, percebendo a importância de ampliar as significações de avaliação.

Posteriormente, Gauer (2004) faz menção à avaliação, porém direciona-se mais para elucidação dos critérios de avaliação dos trabalhos e não na discussão da concepção de avaliação do Movimento Feiras de Matemática. O autor aborda que, tradicionalmente, a avaliação apresentava-se como resultado, como um produto final. Tal afirmação decorre do fato de que o avaliador observa os trabalhos de forma fragmentada, apenas o produto, não o processo de cada trabalho que ali está sendo exposto. Gauer (2004) defendeu, também, a avaliação como processo, mas atendo-se aos critérios que podem levá-la à uma classificação. No mesmo ano, Tomelin (2004) recorda as discussões feitas em coautoria em 2002 e adensa também uma discussão acerca dos critérios.

Os primeiros ensaios no intuito de conceituar a avaliação no Movimento Feiras, baseados em pressupostos teóricos, foram identificados em Scheller e Gauer (2006), que buscaram inicialmente conceituar a avaliação redirecionando o tema para o contexto das Feiras de Matemática. No estudo, os autores defendem que, nas Feiras, avaliar é

[...] analisar o processo de constituição de um trabalho desenvolvido, baseando-se no que é transmitido pelos expositores, no que está relatado em forma escrita e o grau de mudança que este trabalho proporcionou aos alunos. É um momento que deverá levá-los à intervenção, à melhoria, não apenas a apontar problemas ou erros, mas tentar apontar soluções ou sugestões de melhoria. Por isso, mais importante do 
que os resultados serão os encaminhamentos que daremos a eles (SCHELLER; GAUER, 2006, p. 85, grifo nosso).

A partir dessa concepção, os autores defendem que os estudantes e orientadores poderão reconhecer as lacunas existentes em seu trabalho e identificar os aspectos bem desenvolvidos para então se situarem no processo e avançarem em busca de outras informações, subsídios para o desenvolvimento e aperfeiçoamento de seus potenciais cognitivos. O estudo também apontou que a função da avaliação nas Feiras, embora ocorra, geralmente, ao final de um processo, teria aspecto de diagnóstico, de reforço e de permitir o crescimento, bem como considerar o processo como oportunidade de "melhoria contínua" (SCHELLER; GAUER, 2006, p. 86).

Portanto, esses autores corroboram com a segunda corrente de avaliação apontada por Damázio e Tomelin (2002), ou seja, avaliando como processo em que se prioriza uma avaliação formativa em detrimento da classificatória. Assim, a partir do III Seminário, realizado em 2006, se deliberou por uma avaliação mais qualitativa, em que avaliadores teriam a função de emitir parecer descritivo sobre cada trabalho e não apenas atribuir uma nota.

Em 2009, o tema avaliação novamente é discutido na ocasião do IV Seminário sobre Feiras de Matemática, na forma de uma mesa redonda. Silva, Civiero e Silva (2009) abordaram a respeito dos aspectos subjetivos do processo avaliativo, dos avanços no processo de avaliação, dos papéis dos envolvidos para uma melhor avaliação e dos desafios que ainda se apresentam no Movimento. Os membros não discutiram o conceito de avaliação das Feiras, apenas aspectos relacionados a ela. O mesmo ocorre na edição de 2017 do evento.

Já no capítulo de Civiero, Possamai e Andrade Filho (2015), a concepção de avaliação para esses autores deve ser pensada de forma mais ampla e de modo contínuo, com atribuições aos envolvidos em cada um dos momentos. Para eles, esse processo de avaliação é, também, anterior a Feira, quando os autores do trabalho “[...] avaliam e ajustam o trabalho a ser apresentado durante o evento, nos olhares dos professores responsáveis pela avaliação e, após a Feira, quando o professor recebe a síntese da avaliação e pode retomar com seus alunos os pontos destacados nela" (CIVIERO; POSSAMAI; ANDRADE FILHO, 2015, p. 68). No estudo, também destacam que um dos objetivos da avaliação é sugerir melhorias ao trabalho, tal como Damázio e Tomelin (2002) e Scheller e Gauer (2006).

Zabel e Scheller (2019) realizaram um estudo em que constataram que, na avaliação de uma edição de Feira Regional, os avaliadores não conseguiram justificar a indicação dos motivos que levaram um trabalho a ser considerado como menção honrosa, expressão aos 
trabalhos que ainda se encontram em fase inicial ou apresentam falhas ou faltas e que merecem ser retomados. A hipótese das autoras de que esses trabalhos seriam os que mais teriam sugestões ou proposições para continuidade não foi confirmada.

A partir dessas considerações, percebeu-se que a avaliação no Movimento Feiras de Matemática pode ser concebida como um processo que transcende a ideia de classificação ou de seleção, característico de uma avaliação tradicional. Trata-se de um processo cíclico, porém em espiral, em que se busca proporcionar o reconhecimento de informações sobre o trabalho exposto, o estudo sobre potencialidades e possibilidades de melhoria e ampliação dele, a anuência dos avaliadores nas considerações e proposições, a oportunidade da retomada e a continuação da ação avaliativa pelos membros envolvidos no trabalho.

\section{Procedimentos metodológicos}

$\mathrm{Na}$ busca pela compreensão das significações que emergiram dos registros avaliativos dos trabalhos expostos nas Feiras de Matemática a partir dos propósitos de avaliação defendidos no Movimento, é que essa pesquisa foi desenvolvida. Sendo assim, este estudo tem caráter qualitativo (BOGDAN; BIKLEN, 1994; DENZIN; LINCOLN, 1994), destacando aspectos descritivos interpretativos. De acordo com esses autores, a pesquisa qualitativa busca compreender os fenômenos a partir das considerações e percepções dos participantes ou envolvidos, isto é, visa a interpretação dos fenômenos e a atribuição de significados dos dados obtidos ou fenômenos.

Os dados foram constituídos de documentos (GUBA; LINCOLN, 1981; CELLARD, 2008), isto é, fichas de avaliação de trabalhos expostos nas Feiras de Matemática, material este que contém considerações de cada avaliador. O corpus de análise foi composto por informações de 225 fichas, oriundas de 71 trabalhos apresentados em duas edições regionais (21 da regional A e 50 da regional B) no Estado de Santa Catarina, realizadas no período de agosto e setembro de 2017. Os trabalhos foram indicados por códigos, como AT1, AT2, ... AT21 e BT1, BT2, ... BT50. Já os aspectos avaliados e presentes na ficha de avaliação foram apontados por códigos como I, II, III IV ou V. Destaca-se que cada ficha contém parecer descritivo que expressa considerações individuais dos avaliadores a respeito de cinco aspectos, descritos no Quadro 1. 


\begin{tabular}{|l|l|}
\hline $\begin{array}{l}\text { I - Ênfase dada ao conteúdo } \\
\text { matemático, por modalidade }\end{array}$ & $\begin{array}{l}\text { Expressão das percepções a respeito da maneira como aparecem a clareza } \\
\text { e objetividade nas definições e nos conceitos científicos essenciais, bem } \\
\text { como, (i) a aplicabilidade do modelo matemático e/ou nível de inter- } \\
\text { relação proposto, ou (ii) nas operações e propriedades matemáticas } \\
\text { empregadas, ou (iii) na utilização de materiais instrucionais e/ou jogos } \\
\text { didáticos. }\end{array}$ \\
\hline $\begin{array}{l}\text { II - Comunicação (oral e e } \\
\text { escrita) do trabalho }\end{array}$ & $\begin{array}{l}\text { Refere-se a considerações a respeito da clareza, do domínio e da } \\
\text { desenvoltura na apresentação, da adequação da linguagem, da } \\
\text { objetividade, da dinâmica e da disposição dos expositores, bem como da } \\
\text { coerência entre linguagem falada e escrita. }\end{array}$ \\
\hline III - Conteúdo matemático & $\begin{array}{l}\text { Considerações quanto ao domínio do conteúdo matemático desenvolvido } \\
\text { no trabalho de acordo com a categoria e ano escolar (equivalente, no } \\
\text { mínimo). }\end{array}$ \\
\hline IV - Qualidade científica & $\begin{array}{l}\text { Ponderações quanto a organização e sistematização do resumo estendido, } \\
\text { quanto à metodologia e conceitos científicos aplicados e resultados, } \\
\text { sempre considerando o ano escolar e a idade. Também refere-se à } \\
\text { disposição dos elementos da apresentação no estande. }\end{array}$ \\
\hline $\begin{array}{l}\text { V - Relevância Científico- } \\
\text { Avaliações a respeito das contribuições do trabalho para a formação de } \\
\text { conceitos específicos da área, de atitudes e de procedimentos. }\end{array}$ \\
\hline
\end{tabular}

Quadro 1 - Aspectos existentes na ficha de avaliação dos trabalhos expostos na Feira Fonte: Elaborado pelos autores a partir de Regimento (2018).

Os documentos, obtidos mediante consentimento livre e esclarecido junto à comissão responsável pela organização e gestão das Feiras, os quais compuseram o relatório final de cada evento, constituíram os dados. Para facilitar o processo de análise, todas as informações (registros avaliativos) contidas nos documentos foram lidas e transcritas para um arquivo único. A análise foi pautada nos procedimentos da Análise Textual Discursiva (ATD), de Moraes e Galiazzi (2011, p. 7), que "[...] corresponde a uma metodologia de análise de dados e informações de natureza qualitativa com a finalidade de produzir novas compreensões sobre os fenômenos e discursos". Neste caso, o conjunto de procedimentos de análise busca a obtenção de novas compreensões e de novos entendimentos a respeito dos registros avaliativos dos trabalhos expressos pelos avaliadores. Trata-se de um processo autoorganizado que busca evidenciar a significação da avaliação escrita dos trabalhos expostos durante a Feira.

Assim, a análise foi constituída inicialmente por três procedimentos principais: (i) a desmontagem dos textos constituintes do corpus - a unitarização -, obtendo assim as unidades de significado, as quais foram codificadas e organizadas; (ii) o estabelecimento de relações entre as unidades com sentidos próximos, de modo a incluí-las nas categorias; (iii) a captação do emergente, em que a nova compreensão é comunicada e confirmada por meio dos metatextos ou textos descritivos e interpretativos elaborados, permeando fundamentos teóricos, resultados de estudos realizados e fragmentos de dados. A elaboração das 
interpretações ocorreu com base nos fundamentos teóricos a respeito de avaliação e dos preceitos de avaliação da Feira de Matemática.

\section{Resultados e discussões}

A partir do registro dos avaliadores presentes nas fichas de avaliação e dos propósitos da Feira de Matemática em relação à avaliação dos trabalhos expostos, utilizando-se dos procedimentos da ATD, emergiram quatro categorias: 1) avaliação como validação/verificação; 2) avaliação como aferição (diagnóstico); 3) avaliação como desqualificação; 4) avaliação como sugestão/ proposição. Na sequência, serão descritas e discutidas tais categorias, fundamentadas em aporte teórico e ancoradas nos excertos registrados pelos avaliadores nas fichas, bem como na revisão bibliográfica relacionada.

\subsection{Avaliação para verificação/validação}

A partir da análise realizada, identificou-se que os sujeitos compreendem a avaliação como meio para simples validação ou verificação, como uma ação que busca observar em que medida os aspectos relativos a cada um dos itens presentes na ficha estão, ou não, contemplados durante a exposição oral ou escrita dos trabalhos. Tais considerações podem indicar que os avaliadores, a maioria professores e conhecedores do Movimento, transpõem para a Feira um equívoco muito presente nas práticas avaliativas escolares: o avaliar com objetivo de examinar ou medir. Embora a Feira não se constitua em um espaço formal de sala de aula, tal evidência, na avaliação dos trabalhos, corrobora as ideias de Hoffmann (2009) e Luckesi (2011). Os excertos ilustram esse caráter examinador ou verificador atribuído à avaliação:

"Apresentam cálculos com domínio e bem contextualizados. Dentro dos conteúdos da série/ano de estudos” (BT6-III, 2017).

"Os elementos no estande estavam bem organizados, o resumo bem escrito, indo ao encontro com a apresentação. O objetivo, metodologia e resultados estiveram claros" (BT27-IV, 2017)

"Ótima apresentação oral, vai de acordo com a escrita. Mantiveram a mesma postura em todo o momento da apresentação" (BT16-II, 2017)

Tais assertivas são resultados de um processo que envolveu observação e síntese dos dados ou informações a respeito de aspectos do trabalho, tanto na oralidade, quanto na escrita, mas que não transcendem os aspectos da ficha de avaliação. Os avaliadores consideram que a 
avaliação se encerra no momento em que apresentam tais conclusões, o que é, para Luckesi (2011), característico da avaliação como verificação que conduz a um processo de classificação ou seleção. Tal aspecto também pode levar a exclusão e, dentro do Movimento Feiras, Damázio e Tomelin (2002) e Scheller e Gauer (2006) já propunham essa superação.

Nessa direção, a avaliação, quando realizada como aferição, não promove condições ou incita que "[...] o sujeito retire dela consequências novas e significativas" (LUCKESI, 2011, p. 52). Pelo contrário, indica que o processo se finda nesse momento, portanto, configura-se como uma avaliação pontual. Nesse caso, a avaliação é considerada como produto e, se assim permanecer, geralmente não há o que os autores dos trabalhos expostos discutirem ou estudarem após ela finalizada. Desse modo, a avaliação não irá se configurar em um processo colaborativo, nem justificar ou direcionar a continuidade do trabalho quando os registros avaliativos forem levados ao conhecimento dos componentes do trabalho, contrariando o defendido por Civiero, Possamai e Andrade Filho (2015).

Nessa categoria também foram identificados sujeitos avaliadores, que apontaram considerações que podem ser entendidas como validações, ou seja, aquelas que legitimam os aspectos evidenciados nos trabalhos, podendo trazer consigo argumentos ou justificativas que reforçam o que está sendo, ou não, aprovado. Os excertos a seguir ilustram isso.

"O que estava no resumo elas conseguiram transpor, havia relação entre o resumo e o que elas apresentaram” (BT6-IV, 2017).

"Considerando que a modalidade é jogos matemáticos, o trabalho está muito bem estruturado. Instiga o aluno ao raciocínio e a lógica matemática de forma descontraída" (BT28-I, 2017).

“O objetivo não foi identificado” (BT12-IV, 2017).

"O estudo de representações geométricas do dia-a-dia sempre ajuda o aluno a se perceber como sujeito histórico-social e enxergar as coisas a sua volta de outras maneiras. O que é importante!" (BT38-V, 2017).

Percebeu-se também nos protocolos que, quando os avaliadores não validam algum aspecto da ficha de avaliação, a constatação feita pouco irá contribuir para que o "[...] sujeito avaliado reflita sobre si e suas ações a partir da compreensão sobre o próprio desempenho", uma vez que os elementos apresentados não dão conta de subsidiar uma reflexão profunda acerca do trabalho, tampouco possibilitar “[...] o aperfeiçoamento de suas intenções/ações, o que certamente terá reflexos na melhoria do trabalho desenvolvido e, consequentemente, na sua atuação na sociedade em que está inserido e na qualidade de ensino" (SCHELLER; GAUER, 2006, p. 87).

Nas Feiras, similar ao defendido por Hoffmann (2009), pretende-se que o avaliador 
ultrapasse a concepção de alguém que simplesmente "observa" se os itens foram, ou não, alcançados, e passe a atuar "[...] na direção de um educador que propõe ações diversificadas, [...] que provoca, questiona, confronta, exige novas e melhores soluções a cada momento" (HOFFMANN, 2009, p. 75). Agindo dessa forma, acredita-se que o processo irá qualificar-se, bem como todos os envolvidos nele.

Os resultados indicam, ainda, que as ações de avaliação apresentam considerações relacionadas aos itens presentes na ficha de avaliação, como se fosse apenas para conferir ou não tais itens. O avaliador realiza-as, geralmente, acrescendo exemplos ou argumentos para sua abordagem, como ilustra o excerto: “O conteúdo matemático abordado foi superficial para o Ensino Médio, embora seja da série, está pouco aprofundado. Mesmo assim, faltou mostrar claro domínio do conceito, a relação de Euler apareceu descontextualizada da matemática” (AT15-III, 2017). Apesar de o avaliador fazer a observação sobre o conteúdo matemático, suas considerações não extrapolam o caráter apenas verificador, o que contraria o exposto por Hoffmann (2009, p. 17), que "[...] para além da investigação e da interpretação da situação, a avaliação envolve necessariamente uma ação que promova a sua melhoria".

\subsection{Avaliação como aferição}

Em relação a esta categoria, percebeu-se que os avaliadores utilizam a avaliação como oportunidade de examinar o trabalho, trazendo proposições para os autores dos trabalhos tanto no sentido positivo, como negativo, conforme apresentado nos excertos que seguem:

"As crianças demonstraram bastante domínio do conteúdo, apareceram conteúdos além do equivalente à idade. Nota-se que as crianças aprenderam realmente” (BT3-III, 2017).

"O domínio matemático foi visivel durante a apresentação, demonstravam um conhecimento além do nivel escolar em que estão inseridos. Além de dominar toda a parte da geometria, mostraram conhecimentos sobre proporção no momento em que explicaram a maquete da escola" (BT27-III, 2017).

"Compreendo que o conteúdo foi até mais longe que o esperado, com o estudo do tempo de várias perspectivas. O mais interessante é observar a compreensão dos alunos que foi proporcionada provavelmente pelo desenvolvimento do projeto" (BT16-III, 2017).

(o trabalho contempla conteúdo) "Inferior a série que estudam” (BT20-III, 2017).

Diferente das proposições da categoria anterior, nesta categoria os sujeitos fazem considerações que evidenciam resultados de um diagnóstico contemplando aspectos para além daqueles existentes na ficha de avaliação. Ao afirmarem que "as crianças demonstraram bastante domínio do conteúdo, [...]. Nota-se que as crianças aprenderam realmente”, os 
avaliadores apresentam resultados de uma interpretação da visualização ou leitura realizada. Ou seja, os avaliadores transcendem os elementos da ficha de avaliação, interpretando-os a partir da realidade do trabalho avaliado. Afinal, como expressam Carminatti e Borges (2012), a avaliação faz parte da atividade humana de reflexão, portanto, é intencional e aplicável a qualquer prática e em diversas atividades, pois “[...] uma avaliação reflexiva auxilia a transformação da realidade avaliada" (HOFFMANN, 2009, p. 10).

Os avaliadores também fazem apontamentos que acabam por assumir a avaliação apenas como uma oportunidade para aferir se o trabalho apresenta, ou não, determinados aspectos, apontando pontos aquém ou falhos. Ao relatarem que o "Resumo [está] adequado, contempla os objetivos de forma clara, porém a conclusão deixa dúvidas já que o objetivo é informar as pessoas sobre o funcionamento da folha de pagamento. As conclusões faladas são interessantes de comparar quem recebe o salário mínimo apenas com os demais" (BT40IV, 2017), há um início de proposição, uma tentativa de contribuir com os autores para a qualificação, mas o avaliador não consegue concretizá-la. Nesse caso, os envolvidos perdem oportunidade para evoluírem no trabalho e o avaliador também perde quando deixa transparecer suas fragilidades diante da tarefa de "avaliar para promover", como Hoffmann (2009) explicita.

Por fim, nessa categoria houve tentativas para além de diagnosticar/aferir. No entanto, elas acabaram apresentando-se com sentido vago, como é o caso dos excertos:

"Faltou abordar mais conceitos de matemática, apresentaram muita teoria e apenas os resultados dos cálculos” (AT19-III, 2017).

"Não está de acordo com o nível escolar, ressaltando que poderia ter abordado mais conteúdos matemáticos" (AT18-III, 2017).

"Trabalha os conteúdos matemáticos, mas não se vê uma aplicabilidade desse aprendizado. O porquê é importante aprender estes conteúdos" (AT13-V, 2017).

Percebe-se que as unidades de significado pertencentes a essa categoria foram empregadas pelos avaliadores para trabalhos que, na visão deles, são os que mais necessitam de melhorias, geralmente como uma justificativa para trabalhos não completos. No entanto, ainda se caracterizam como mero diagnóstico, pois ficam apenas na tentativa de proposição ou sugestão de melhoria.

Pode-se inferir, então, que essa perspectiva de avaliação nas Feiras necessita ser remodelada ou reconfigurada, pois “[...] o papel do avaliador, [...] transforma-se no de partícipe do sucesso ou fracasso dos alunos, uma vez que os precursores individuais serão mais ou menos favorecidos a partir de suas decisões pedagógicas que dependerão, igualmente, 
da amplitude das observações" (HOFFMANN, 2009, p. 17-18). Afinal, o julgar está mais próximo de controlar o processo do que de promover aprendizados. No entanto, deve-se lutar por uma avaliação que projete e vislumbre o futuro, a evolução das aprendizagens. Para a autora, olhar para o futuro significa planejar alternativas para o melhor desenvolvimento de cada trabalho, emitindo considerações embasadas em princípios éticos, políticos e estéticos.

\subsection{Avaliação como desqualificação}

Nesta categoria, identificaram-se considerações dos avaliadores que vão na contramão do almejado pelas Feiras de Matemática. Isto porque observam-se elementos que não contribuem para a continuidade do trabalho ou reflexão sobre ele, aproximando-se de uma avaliação quantitativa com descrições nada coerentes em termos de argumentos, com a utilização de expressões como "muito bom", "atende", "não atende", dentre outras. Considerações superficiais e genéricas desse nível nada podem contribuir para promover aprendizagens a patamares superiores. Algumas considerações vão além, porém apenas apontam erros, falhas ou problemas sem evoluir para proposições ou sugestões, sendo desprovidas de argumentação, como as que seguem:

"Não apresentavam domínio. Sem muitos conteúdos” (AT8 - III, 2017).

"Não tinha muita clareza nos conceitos de matemática. Não tinha muito objetivo específico. Não relacionaram as disciplinas" (AT8 - I, 2017).

“Não souberam alguns detalhes importantes" (AT9 - IV, 2017).

“Fica a desejar no resumo" (AT7 - IV, 2017).

“Aparentemente decorado” (AT18 - II, 2017).

Entende-se que para realizar tais considerações os avaliadores fizeram um diagnóstico, inicialmente, tanto da oralidade, quanto do relato escrito. No entanto, ele não contribuiu para uma avaliação formativa, uma vez que esse tipo de avaliação “[...] dá informações, identifica erros, sugere interpretações quanto às estratégias e atitudes dos alunos e, portanto, alimenta diretamente a ação pedagógica" (PERRENOUD, 1999, p. 68), o que não é observado nos trechos. Tais considerações dos avaliadores podem indicar uma relação muito íntima com a avaliação classificatória que não se preocupa em expressar anotações significativas a respeito do que foi avaliado.

Assim como nas avaliações para verificação/validação, as considerações apontadas pelos avaliadores nessa categoria corroboram a perspectiva de avaliação meritocrática e 
classificatória, como se a ficha de avaliação fosse um check list para verificar o que o trabalho atende ou não atende, distanciando-se de uma avaliação para promover. Tal forma de avaliar, conforme evidenciado por Hoffmann (2009), está muito próxima da necessidade que os professores sentem de coletar evidências comprováveis dos expositores para tomarem decisões finais sobre ser ou não ser destaque. Ou seja, os avaliadores, que são, em sua maioria, professores da Educação Básica, transpõe essa necessidade (de reprovar ou aprovar) na avaliação dos trabalhos expostos.

\subsection{Avaliação como proposição/sugestão}

Nesta categoria identificamos considerações que exprimem a ideia de avaliação como processo, como ação que visa conhecer para promover, e não para classificar. Os avaliadores, em seus apontamentos, buscam propor algo, sugerir ou apontar/informar encaminhamentos para continuação do trabalho, instigar os autores para que destaquem, no trabalho, argumentos mais coerentes para situações apresentadas e maior riqueza de detalhes nos procedimentos realizados, bem como maior precisão de procedimentos ou estratégias de resolução.

As considerações apresentadas pelos avaliadores corroboram com a perspectiva de Feira de Matemática apresentada por Damázio e Tomelin (2002, p. 42), que a identifica como

um momento de socialização dos conhecimentos matemáticos e experiências pedagógicas produzidos pelos expositores e orientadores. [...] uma oportunidade de submeter os trabalhos à apresentação do público e da comissão de avaliação, em busca de sugestão para aprimoramento e continuidade da pesquisa.

Neste sentido, os excertos a seguir representam a ideia apresentada pelos autores:

"O próximo passo do projeto seria o cálculo de áreas e volumes dos sólidos construidos para elaborar uma maquete proporcional, calculada pelos próprios alunos” (BT27 - III, 2017).

"Acho interessante explorar os gráficos de custo e do lucro na apresentação, bem como os gráficos de comparação entre a máquina alugada e comprada” (BT42 - III, 2017).

A minha única sugestão é a realização de outras atividades do mesmo caráter ou a elaboração de uma dinâmica para explicar a técnica da pintura anamórfica para quem assiste, visando deixar a apresentação mais elaborada" (AT6 - V, 2017).

Quando os autores recebem considerações como as ilustradas anteriormente, acreditase que possam discutir e refletir sobre o que foi realizado/exposto e o que foi proposto pelos avaliadores para o redimensionamento das ações e para a continuação do projeto. Assim, a avaliação contribui para a orientação, uma vez que pode expressar aspectos ainda não percebidos ou diagnosticados pelo orientador do trabalho, tais como fragilidades, 
potencialidades, oportunidades de reorganização de dados e informações, evolução de ideias ainda incipientes, dentre outros. Oliveira et al. 2012 já destacou que, ao se promover o retorno da ficha de avaliação para orientadores visando uma retroalimentação das atividades de orientações futuras, algumas proposições devem ser feitas pensando na qualificação da apresentação do trabalho ou de conteúdo matemático que pode ser acrescentado ou mais aprofundado, conforme ilustram os excertos a seguir.

"Explorar um pouco mais a construção de tabelas e gráficos e do próprio cálculo da regra de três" (BT29 - III, 2017).

"A profundidade científica foi superficial, por se tratar de matemática pura é preciso aprofundar o conceito, a fórmula de Euler e sua demonstração" (AT15 - V, 2017).

"Reduzir o conteúdo a ser apresentado, evitando o cansaço das crianças. Mais objetividade" (AT36 - II, 2017).

"Poderiam explorar um pouco mais as formas de trabalhar porcentagem, pensando isso para um próximo trabalho, visando a capacidade das meninas é que sugiro isso, pois mostraram total domínio sobre como calcular porcentagem" (BT5 - III, 2017).

As avaliações propositivas contribuem para a continuidade do projeto ao retornarem para o espaço escolar, uma vez que indicam possibilidades para ele. Entende-se que esse tipo de avaliação possibilita a reflexão sobre o processo. Assim, sendo a avaliação e reflexão capacidades do ser humano, é possível “[...] pensar sobre seus atos, de analisá-los, julgá-los, interagindo com o mundo e com os outros seres, influindo e sofrendo influências pelo seu pensar e agir [...] Uma avaliação reflexiva auxilia a transformação da realidade avaliada" (HOFFMANN, 2009, p. 10).

Nessa categoria de análise, ainda pouco recorrente nos documentos analisados, foram identificados avaliadores comprometidos com o processo da feira, que conseguem pensar a avaliação de forma continuada e não pontual. Tais avaliadores entendem que a avaliação é “[...] um processo a ser construído pelo diálogo, pelo encontro, pelo confronto, por pessoas em processo de humanização" (VASCONCELLOS, 2009, p. 11). Acredita-se que os sujeitos que primam por este tipo de avaliação tenham concepções epistemológicas diferentes daqueles que apenas aferem aspectos. Afinal, como destaca o autor, o ato de avaliar na vida cotidiana ocorre permanentemente pela unidade imediata de pensamento e ação, a partir de juízos, opiniões assumidas como corretas e que ajudam nas tomadas de decisões. Ao fazer juízo visando uma tomada de decisão, o ser humano coloca em funcionamento os seus sentidos, sua capacidade intelectual, suas habilidades, sentimentos, paixões, ideais e ideologias. Nessas relações estão implícitos tanto aspectos pessoais dos indivíduos, como também aqueles adquiridos em suas relações sociais. Portanto, há que se investir em formação 
para que o Movimento Feiras garanta a avaliação como processo qualitativo, coletivo, colaborativo e formativo.

\subsection{Um panorama da avaliação nas duas regionais}

Depois de buscar compreender as significações que emergem dos registros de avaliação dos trabalhos expostos nas duas Feiras Regionais, considera-se necessário tecer algumas considerações acerca do panorama geral que a análise possibilitou. Nesse panorama, relacionam-se as formas desse registro com os itens da ficha de avaliação e com as categorias em que os trabalhos podem ser inscritos para a socialização.

Em relação ao conjunto das unidades de significados relativas à Regional $\mathrm{A}$, oriundas de 21 trabalhos expostos, as considerações dos 25 avaliadores foram feitas principalmente no sentido de aferição (46,6\%) e de verificação/validação (26,8\%), enquanto as sugestões alcançam apenas 9,4\%. De modo geral, os avaliadores emitiram mais considerações para o segundo item da ficha de avaliação, comunicação do trabalho (23,2\%). No entanto, foram mais propositivos no aspecto qualidade científica $(35,4 \%)$.

Percebeu-se que aqueles que apontam sugestões/proposições apresentam um estilo de escrita mais estruturada/qualificada, com expressões suavizadas e quase isentas de aspectos que desqualificam o trabalho, como apontamento de erros, falhas ou inconsistências de forma agressiva. Assim, nessa regional, a avaliação foi utilizada basicamente para medir, classificar e examinar. No item em que foram emitidas mais considerações, comunicação do trabalho, observou-se que a maior parte delas são percepções obtidas na oralidade, não no trabalho escrito (relato de experiência), fato que indica o quanto na Feira prevalece a oralidade.

No que se refere às categorias, ainda nessa regional, os 11 avaliadores de trabalhos dos Anos Iniciais foram os que mais emitiram considerações que desqualificavam, enquanto que nas fichas de avaliação dos Anos Finais observou-se maior número de registros com excesso de considerações vagas, não deixando sugestões ou proposições para a continuidade do trabalho. Já o Ensino Médio foi a categoria que recebeu mais proposição para qualificação do trabalho, sendo a categoria em que o número de validações, aferições e proposições foram mais equilibradas. Portanto, esses avaliadores apresentam características com os ideais de avaliação do Movimento Feiras de Matemática.

Quando o foco é a Regional B, os registros avaliativos dos 50 trabalhos elaborados por 37 avaliadores, dispostos em 12 grupos, contêm considerações mais densas e em maior quantidade que os da Regional A. No entanto, similar à primeira região, as considerações 
concentraram-se nos sentidos de aferição (50,2\%) e de verificação/validação (31\%), embora nessa regional as sugestões tenham alcançado maior valor (13,1\%). Observou-se que os avaliadores também emitiram mais considerações para o segundo item, comunicação do trabalho $(24,7 \%)$, contudo foram mais propositivos no aspecto conteúdo matemático $(27,7 \%)$. $\mathrm{Na}$ Regional B, a avaliação foi utilizada também para medir, classificar e examinar, porém com maior quantidade de proposições comparadas à outra.

No que diz respeito às categorias, foi no Ensino Médio que os avaliadores mais emitiram ponderações que desqualificavam o trabalho, fortemente evidenciado no item que se refere ao conteúdo matemático. O excesso de considerações vagas e isentas de contribuições para a continuidade do trabalho foi mais verificado na categoria Educação Especial. Já Anos Iniciais foi a categoria em que se identificou maior número de observações para melhoria e ampliação do trabalho.

\section{Considerações finais}

Para realizar essa investigação, analisaram-se as fichas de avaliação de duas Feiras Regionais de Matemática, tendo como foco compreender a significação que emerge dos registros de avaliação dos trabalhos expostos na Feira. Nesse processo, identificou-se que os avaliadores compreendem diferentemente o significado da avaliação. Emergiram quatro categorias de análise: avaliação como validação/verificação; avaliação como aferição; avaliação como desqualificação e avaliação como sugestão/proposição, conforme Quadro 2.

\begin{tabular}{|l|l|}
\hline $\begin{array}{c}\text { 1) Avaliação para } \\
\text { validação/verificação }\end{array}$ & $\begin{array}{l}\text { Considerações que confirmam/verificam os propósitos presentes nos itens de } \\
\text { avaliação, ou seja, apresentam informações sobre o trabalho apenas com base nos } \\
\text { indicadores de cada item presente na ficha. }\end{array}$ \\
\hline $\begin{array}{l}\text { 2) Avaliação como } \\
\text { aferição }\end{array}$ & $\begin{array}{l}\text { Apontamentos sobre o trabalho de aspectos que geralmente fogem da realidade } \\
\text { esperada, ou seja, não apenas como base nos itens de avaliação da ficha, como na } \\
\text { categoria 1. Nesse caso, as considerações trazem um diagnóstico do trabalho, } \\
\text { relatando pontos aquém ou falhos e sendo uma tentativa ou subsídio para possível } \\
\text { sugestão ou proposição, mas ficando no sentido vago. }\end{array}$ \\
\hline $\begin{array}{l}\text { 3) Avaliação como } \\
\text { desqualificação }\end{array}$ & $\begin{array}{l}\text { Considerações que apenas apontam erros, falhas ou problemas, sem evoluir para } \\
\text { proposições ou sugestões. São desprovidas de argumentação e pouco ou nada } \\
\text { agregam ao trabalho ou ao processo despendido. }\end{array}$ \\
\hline $\begin{array}{l}\text { 4) Avaliação como } \\
\text { proposição/sugestão }\end{array}$ & $\begin{array}{l}\text { Considerações cujo sentido foi propor algo, sugerir ou apontar encaminhamentos } \\
\text { para continuação do trabalho, visando ampliação e/ou qualificação do mesmo. Nesta } \\
\text { categoria, o avaliador geralmente utiliza de exemplos ou argumentos para fazê-la. }\end{array}$ \\
\hline
\end{tabular}

Quadro 2 - Categorias emergentes do processo de análise e o significado de avaliação. Fonte: Elaborado pelos autores (2019). 
As ações de avaliar imbuídas de sentido de aferir (2) e/ou validar (1), no geral, são as que dão início a um movimento de explicitação para as demais ou as baseiam, portanto, constituem-se como centrais. No entanto, no decorrer da avaliação, pode haver extrapolação dessas, culminando em outra significação, que pode permanecer com o sentido conceituado na categorização, bem como pode apenas apresentar considerações decorrentes da extrapolação dos sentidos de aferição e/ou validação, sem a presença destas.

Nas ações imbuídas de desqualificar (3), a avaliação pode ter efeito reverso do que deveria, causando frustrações e desistências da participação neste tipo de evento. Já nas ações de avaliar com sentido de propor ou sugerir (4), o avaliador faz considerações para além do constatado e que irão contribuir para a ampliação ou qualificação do trabalho, constituindo-se desafios para seus autores. Nesse tipo de registro, o avaliador assume papel principal no processo, se fazendo presente verdadeiramente. São essas considerações que propiciarão a qualificação do trabalho e o desenvolvimento dos autores, pois dessa forma o avaliador irá instigá-los a refletirem sobre ideias e ampliarem o pensamento, questionar para obter novas compreensões, avançar com suas explicações ou estratégias utilizadas para alcance do objetivo do trabalho. Tais considerações ocorreram mais no item conteúdo matemático.

Nesse sentido, a análise realizada permite caracterizar as ações do avaliador durante o momento em que ocorre a exposição dos trabalhos, bem como ensaiar as suas concepções. Sordi (2001) afirma que uma avaliação espelha um juízo de valor, uma dada concepção de mundo e de educação e, por isso, vem impregnada de um olhar absolutamente intencional que revela quem é o educador quando interpreta os eventos da cena pedagógica. Assim, quando são observadas as avaliações que apenas validam ou desqualificam os trabalhos, entende-se que elas são fruto de uma concepção da pedagogia tradicional e tecnicista, uma vez que classificam e examinam os trabalhos.

Percebe-se que a concepção dos avaliadores que exprimem tais considerações não é pertinente para a melhoria, aprofundamento e ampliação do trabalho exposto, que é o foco principal da socialização nas Feiras de Matemática. Tais categorias dão indícios de que os avaliadores ainda estão preocupados em apenas determinar se o trabalho é destaque ou menção honrosa, ou seja, classificar. Quando isso acontece, o avaliador deixa de fazer a proposição após ter realizado o diagnóstico ou validado as informações, não apresentando argumentos suficientes e convincentes para justificar o resultado. Assim, ele esquece que deve haver um elo entre as considerações avaliativas e os autores do trabalho avaliado, uma vez que estes receberão as fichas de avaliação após o evento.

Destacamos que uma das contribuições desta pesquisa refere-se aos subsídios que ela 
fornece para a formação de professores e avaliadores participantes das Feiras de Matemática, tanto em nível regional, quanto em nível nacional. Os resultam indicam a necessidade da criação de um programa de formação/qualificação permanente acerca da avaliação dos trabalhos nas Feiras para avaliadores, coordenadores de grupos e professores orientadores de trabalho. Esse programa deve subsidiar as ações dos avaliadores para a elaboração de um feedback no qual sejam evidenciados, principalmente, os elementos considerados na categoria Avaliação como proposição/sugestão e desse modo, superar as implicações negativas de um feedback que apenas desqualifica o realizado e ou é isento de aspectos que subsidiam o avanço do trabalho.

Ainda, essa reflexão sobre o processo avaliativo dos trabalhos apresentados nas Feiras junto com avaliadores e orientadores e também pode contribuir para o rompimento de formas tradicionais de avaliação realizadas por eles em sala de aula. Ou seja, o processo avaliativo dos trabalhos em Feiras de Matemática pode favorecer o desenvolvimento profissional do professor, se este estiver receptivo para tal, no que tange às formas de avaliar, priorizando as mais qualitativas e inclusivas.

Destaca-se que os resultados poderiam ter sido diferentes caso fosse analisada outra edição do evento, com outros avaliadores, visto o caráter rotativo que os participantes têm na Feira e o seu momento de expansão. Em relação às perspectivas de continuidade, acredita-se que a demanda seja ainda ampla, uma vez que poucas e recentes são as pesquisas realizadas a respeito do Movimento Feiras de Matemática. Tais pesquisas podem trazer contribuições para campos de investigação relacionados ao currículo, ao desenvolvimento profissional de professores, à cognição dos expositores e aos processos de ensino em sala de aula. Sugere-se algumas questões que podem ser desenvolvidas para ampliar e/ou contribuir com as que já existem. Eis algumas delas:

- Em algumas fichas, percebeu-se que não havia nada escrito em alguns itens de avaliação. $\mathrm{O}$ que isso pode indicar? Que está bom ou que o avaliador não tem argumentos para emitir considerações? Como os autores do trabalho podem interpretar isso?

- Destaca-se que as considerações dos avaliadores com caraterísticas de examinar são, em maioria, sobre aspectos observados na apresentação oral do trabalho. No entanto, em que medida a avaliação também deve considerar a parte escrita?

- Em uma avaliação em que um trabalho é considerado "bom", porém ainda precisa avançar em alguns elementos devido ao potencial que apresenta, por que este trabalho, na maioria das vezes, não é indicado para a etapa seguinte se tem potencialidade para melhorar, aprofundar e avançar? Isso garantiria uma avaliação processual? 
- Detectaram-se aspectos de avaliação propositiva nas fichas individuais, as quais não foram contempladas no relatório síntese (ainda que não tenha sido objeto de estudo desta pesquisa). Estaria o coordenador do grupo avaliativo ciente da importância do seu papel nesse processo de avaliação?

- Breuckmann (1996) já discutia que a avaliação deveria basear-se em fontes diversas. No entanto, sabe-se que na prática não é sempre que isso acontece. A linguagem oral ainda se mostra como a maior fonte de informações sobre o trabalho. Seria pertinente uma maior valorização da escrita (resumo, portfólio, pôster, dentre outros) do trabalho ou um equilíbrio entre oral e escrito?

- Como, de fato, romper com a avaliação classificatória e garantir uma avaliação formativa dos trabalhos apresentados nas Feiras de Matemática, assegurando os princípios do Movimento?

\section{Referências}

BIEMBENGUT, M. S.; ZERMIANI, V. J. Feiras de Matemática: História das Ideias e Ideias da História. Blumenau: Legere/Nova Letra, 2014.

BREUCKMANN, H. J. Avaliação de trabalhos: uma longa caminhada. Revista catarinense de Educação Matemática, Blumenau, v. 1. n.1, p. 25-28,1996.

BOGDAN, R.; BIKLEN, S. Investigação Qualitativa em Educação: uma introdução à teoria e aos métodos. Portugal: Porto Editora, 1994.

CARMINATTI, S. S. H; BORGES, M. K. Perspectivas da avaliação da aprendizagem na contemporaneidade. Est. Aval. Educ., São Paulo, v. 23, n. 52, p. 160-178, mai./ago. 2012.

CELLARD, A. A análise documental. In: POUPART, J. et al. (org.). A pesquisa qualitativa: enfoques epistemológicos e metodológicos. Petrópolis: Vozes, 2008. p. 295-316.

CIVIERO, P. A. G.; POSSAMAI, J. P.; ANDRADE FILHO, B. M. Avaliação nas feiras de matemática: processo de reflexão e cooperação. In: HOELLER, S. A. O. et al. (org.). Feiras de Matemática: percursos, reflexões e compromisso social. Blumenau: IFC, 2015. p. 67-86.

DAMÁZIO, A.; TOMELIN, L. Z. Como avaliar um trabalho. In: STIELER, L. K. Seminário de avaliação das Feiras Catarinenses de Matemática. Brusque/Blumenau: Edifurb, 2002. p. 84-93.

DENZIN, N. K.; LINCOLN, Y. S. (Eds.). Manual de Pesquisa Qualitativa. Thousand Oaks: Sage Publications, 1994.

GAUER, A. J. Critérios de avaliação de trabalhos em Feiras de Matemática: um olhar voltado para o processo. In: ZERMIANI, V. J. (org.). Feiras de Matemática: Um programa científico \& social. Blumenau: Acadêmica, 2004. p. 27-58.

GUBA, E. G.; LINCOLN, Y. S. Effective Evaluation. São Francisco: Jossey-Bass, 1981.

HADJI, C. Avaliação desmistificada. Porto Alegre: Artmed Editora, 2001.

HOFFMANN, J. Avaliar para promover: as setas do caminho. Porto Alegre: Mediação, 2009. 
LUCKESI, C. A avaliação da aprendizagem escolar: estudos e proposições. 22. ed. São Paulo: Cortez, 2011.

MORAES, R.; GALIAZZI, M. C. Análise textual discursiva. 2. ed. Ijuí: Unijuí, 2011.

OLIVEIRA, F. P. Z. et al. Um diferencial em eventos científicos e tecnológicos: o processo de avaliação na FETEC e em Feiras de Matemática. In: MOSTRA DE PESQUISA E EXTENSÃO DO IF CATARINENSE, 2., 2012, Rio do Sul. Anais... Rio do Sul: IFC, 2012. p. 1-12.

PERRENOUD, P. Avaliação: da excelência à regulação das aprendizagens - entre duas lógicas. Porto Alegre: Artmed, 1999.

REGIMENTO DA VI FEIRA NACIONAL DE MATEMÁTICA. 2018. Disponível em: http://www.furb.br/_upl/files/especiais/lmf/feira_nacional/REGIMENTO\%20VI\%20FNMAT\%20(1).p df?20180530183803. Acesso em: 30 mai. 2018.

SCHELLER, M.; GAUER, A. J. Avaliação em feiras de matemática: olhando para o interior da prática avaliativa. In: ZERMIANI, V. J. (org.). III Seminário de avaliação das Feiras Catarinense de Matemática. Blumenau: Odorizzi, 2006. p. 83-95.

SILVA, H. S.; CIVIERO, P. C.; SILVA, V. C. 2009. A avaliação nas feiras de Matemática. In: ZERMIANI, V. J. (org.). Anais do IV Seminário sobre Feiras de Matemática e XXIV Feira Catarinense de Matemática. Blumenau: Nova Era, 2009. p. 49-56.

SILVA, V. C.; GARNICA, A. V. M. Mostruário de Práticas: considerações sobre a formação e a atuação de professores dos Anos Iniciais a partir das Feiras Catarinenses de Matemática.

Bolema, Rio Claro, v. 29, n. 53, p. 909-935, dez. 2015.

SILVA, V.; POSSAMAI, J. P. Avaliação dos trabalhos nas Feiras de Matemática: uma atividade colaborativa e processual. Rematec, Belém, v. 14, n. 30, p. 106-120, 2019.

SORDI, M. R. L. de. Alternativas propositivas no campo da avaliação: por que não? In: CASTANHO, S.; CASTANHO, M. E. (org.). Temas e textos em metodologia do Ensino Superior. Campinas: Papirus, 2001. p. 171-182.

TOMELIN, L. Z. A avaliação de trabalhos nas feiras de matemática. In: ZERMIANI, V. J. (org.). Feiras de Matemática: Um programa científico \& social. Blumenau: Acadêmica, 2004. p. 151-162.

VASCONCELLOS, M. M. M. Avaliação \& ética. 2. ed. Londrina: Eduel, 2009.

ZABEL, M.; SCHELLER, M. Uma análise dos relatórios síntese de avaliação de uma Feira Regional de Matemática. In: ENCONTRO NACIONAL DE EDUCAÇÃO MATEMÁTICA (ENEM), 13., 2019, Cuiabá. Anais... Cuiabá: SBEM - MT, 2019. p. 1-16 Disponível em: https://sbemmatogrosso.com.br/eventos/index.php/enem/2019/paper/view/831/439. Acesso em: 23 nov. 2019.

ZERMIANI, V. J. Histórico das Feiras Catarinenses de Matemática. Revista catarinense de Educação Matemática, Blumenau, v. 1. n.1, p. 10-17,1996.

ZERMIANI, V. J.; JUBINI, G. M.; SOUZA, R. G. A matemática e as feiras em Santa Catarina. In: HOELLER, S. A. O. et al. (org.). Feiras de Matemática: percursos, reflexões e compromisso social. Blumenau: IFC, 2015. p. 67-86. 